\title{
Synthesis and Thermotropic Liquid Crystalline Behavior of Novel Main-Chain Poly(aryl ether ketones) Copolymer Containing Phthalazinone Moiety and Biphenyl Mesogen
}

\author{
By Qingmin SUN, ${ }^{1,2}$ Jinyan WANG, ${ }^{1,2}$ Kejia JIN, ${ }^{1,2}$ Guixian SU, ${ }^{1,2}$ Guanghui LI, ${ }^{1,2}$ and Xigao JIAN ${ }^{1,2, *}$
}

\begin{abstract}
A novel thermotropic liquid crystalline poly(aryl ether ketones) copolymer containing phthalazinone moiety and biphenyl mesogen named P-5050 was developed by a mild solution polycondensation reaction. The thermotropic liquid crystalline properties were characterized by the means of differential scanning calorimetry (DSC), polarized light microscopy (PLM) and wide-angel X-ray diffraction (WAXD). A thread-like texture was achieved when P-5050 was annealed at $320^{\circ} \mathrm{C}$ for $1 \mathrm{~h}$, and a typical schlieren texture was observed when shear forces were induced at that temperature. The crystalline-to-liquid crystalline transition $\left(T_{\mathrm{m}}\right)$ and the liquid crystalline-to-isotropic phase transition $\left(T_{\mathrm{i}}\right)$ appeared in both the first cooling and second heating DSC thermograms. The glass transition temperature $\left(T_{\mathrm{g}}\right)$ was $160{ }^{\circ} \mathrm{C}$ and the value for $5 \%$ weight loss temperature was $510^{\circ} \mathrm{C}$ in nitrogen from DSC and TGA determinations, respectively.

KEY WORDS: Copolymerization / Phthalazinone / Thermotropic Liquid Crystalline Polymers (LCPs) / Poly(aryl ether ketones) /
\end{abstract}

High performance engineering thermoplastics containing phthalazinone unit have been explored for a long time since Berard and Hay reported the synthetic method of DHPZ, ${ }^{1}$ and many kinds of materials bearing phthalazinone were accomplished, such as PPEK, PPES, PPEKK, PPESK, PA, PI et al. ${ }^{2-13}$

It is well-known that liquid crystalline properties are particularly valuable in the applications of high performance engineering materials. For example, the melt viscosities of thermotropic liquid crystalline polymers (LCPs) possessing an isotropic melt state were significantly lower than structurally similar polymers. ${ }^{14-16}$ In addition, LCPs were also attached importance to their high modulus and a very low thermal expansion in their direction of the macroscopic orientation.

A series of thermotropic liquid crystalline poly(aryl ether ketones) copolymers have been prepared since Bennett and Farris firstly reported a kind of thermotropic liquid crystalline poly(aryl ether ketones) copolymers based on 4, 4'-biphenol, bulky substituted hydroquinone and 4, 4'-difluorobenzophenone in $1994 .{ }^{17-22}$

Quite recently, a novel kind of lyotropic liquid crystalline poly(aryl ether ketones) copolymer and several kinds of polyamides containging phthalazione structure which possessed nematic lyotropic liquid crystalline properties were firstly described in our works. ${ }^{9-11,13}$

In the present paper, a novel kind of nematic thermotropic liquid crysatlline poly(aryl ether ketones) copolymer was prepared by a one-step mild solution polycondensation reaction with 4-(4-hydroxyl-phenyl)(2H)-phthalazin-1-one (DHPZ), 4, 4'-biphenol (BP) and 1, 4-bis(4-fluorobenzoyl)-benzene (BFBB). The structure and liquid crystalline behaviors of the poly(phthalazinone ether biphenyl ketone ketone) copolymer were also investigated in detail.

\section{EXPERIMENTAL}

\section{Materials}

4-(4-hydroxylphenyl)(2H)-phthalazin-1-one (DHPZ) was synthesized according to the procedure reported previously. ${ }^{1}$ The product was obtained as white powders; mp: 310$310.8^{\circ} \mathrm{C}$; yield: $90 \mathrm{wt} . \%$ (weight percent); the product was confirmed by MALDI-TOF/MS. GC/MS $\left(\mathrm{M}^{+}\right.$calcd as $\mathrm{C}_{14} \mathrm{H}_{10} \mathrm{O}_{2} \mathrm{~N}_{2}$ 238.0742) $m / z=238.0750 \quad\left(\mathrm{M}^{+}\right)$. 1, 4-bis(4fluorobenzoyl)benzene (BFBB) was prepared according to the reported method. ${ }^{23}$ The product was obtained as white pellets; mp: $220.2-221.2^{\circ} \mathrm{C}$; yield: $90 \mathrm{wt} \%$; the product was confirmed by MALDI-TOF/MS. GC/MS $\left(\mathrm{M}^{+}\right.$calcd as $\mathrm{C}_{20} \mathrm{H}_{12} \mathrm{O}_{2} \mathrm{~F}_{2}$ 322.0805) $m / z=322.0804\left(\mathrm{M}^{+}\right)$. 4, 4'-biphenol (BP) was purchased from Aldrich and used without further purification. Anhydrous potassium carbonate (Beijing Chemical Co., A.R.) was ground and dried in vacuum at $100^{\circ} \mathrm{C}$ for $24 \mathrm{~h}$ before use. Sulfolane (Beijing Chemical Co., A.R.) was dried and distilled over sodium hydroxide pellets (Beijing Chemical Co., A.R.) under reduced pressure, then the middle fractions were collected and stored over molecular sieves (type $4 \AA$ ) before use. Unless otherwise specified, all other solvents and reagents were purchased from Beijing Chemical Co. and used as received.

Sample Preparation for WAXD and SAXD Measurements 1. The crystalline sample was prepared by annealing the film sample for $2 \mathrm{~h}$ at $300^{\circ} \mathrm{C}$ and cooling it to room temperature naturally.

2. The amorphous sample was prepared by annealing the film sample for $10 \mathrm{~min}$ at $410^{\circ} \mathrm{C}$ and putting it into an ice/water mixture immediately.

\footnotetext{
${ }^{1}$ Department of Polymer Science and Materials, Dalian University of Technology, Dalian 116012, People's Republic of China

${ }^{2}$ Liaoning Province Engineering Center of High Performance Resins, Dalian 116012, People's Republic of China

*To whom correspondence should be addressed (Tel/Fax: 86411 83639223, E-mail: jian4616@dl.cn).
} 
<smiles>[X]c1ccc(-c2n[nH]c(=O)c3ccccc23)cc1</smiles>

DHPZ

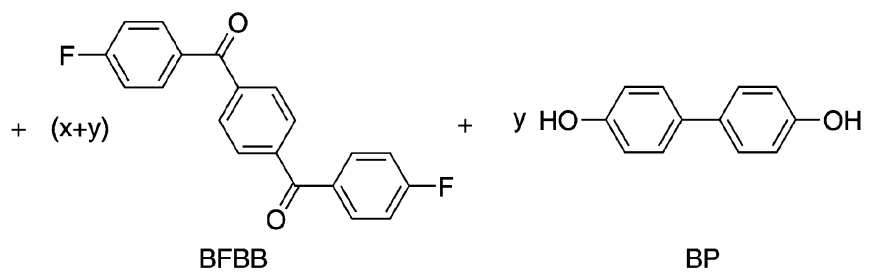

200-220 ${ }^{\circ} \mathrm{C} \mid \begin{gathered}\mathrm{K}_{2} \mathrm{CO}_{3} \\ \text { Sulfonlane }\end{gathered}$

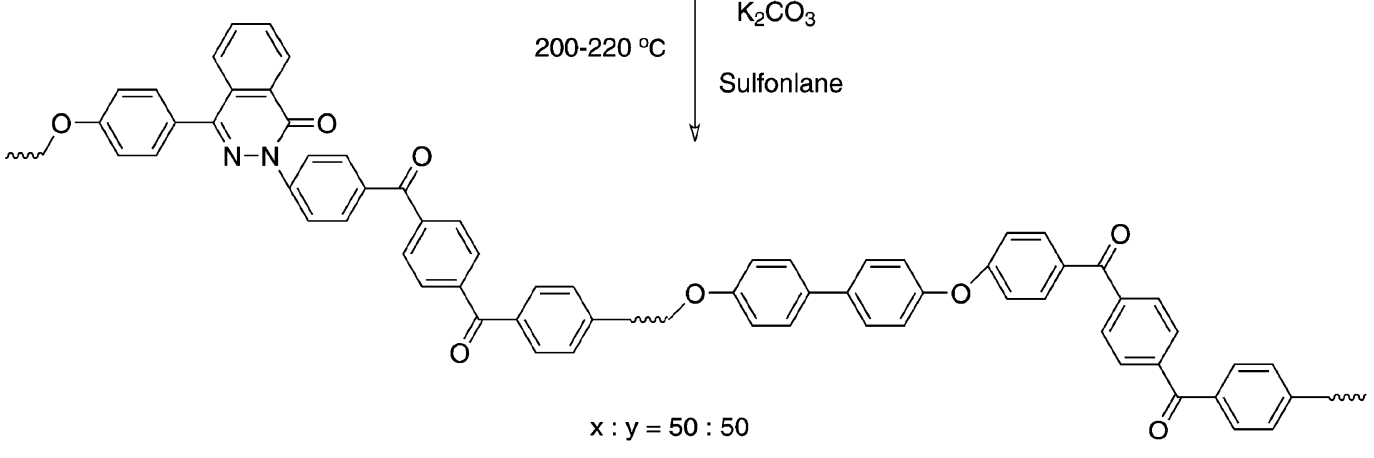

Scheme 1. The synthetic route of P-5050.

3. The liquid crystalline sample was prepared by annealing the film sample for $10 \mathrm{~min}$ at $410^{\circ} \mathrm{C}$, then cooling it to $320^{\circ} \mathrm{C}$ at $10^{\circ} \mathrm{C} \mathrm{min}{ }^{-1}$, annealing it for $1 \mathrm{~h}$ at $320^{\circ} \mathrm{C}$ and putting it into an ice/water mixture immediately.

\section{Measurements}

Elemental Analysis was measured on a Vario EL III CHNOS Elementaranalysator from Elementaranalysesyteme $\mathrm{GmbH}$. Matrix-assisted laser desorption ionization time-offlight mass spectroscopy (MALDI-TOF/MS) analyses were performed on a Micromass GC-TOF CA 156 MALDI-TOF/ MS. The $M_{\mathrm{n}}$ of the copolymer was determined by ${ }^{19} \mathrm{~F}$ NMR with the spectra being obtained by the use of a Varian Unity Inova 400 spectrometer operating at $376.067 \mathrm{MHz}$ at $25^{\circ} \mathrm{C}$. The sample solution $(\sim 5 \%)$ in concentrated sulfric acid was prepared at room temperature, with sodium trifluoroacetate used as the internal standard. Thermogravimetric analysis (TGA) and derivative thermogravimetric analysis (DTG) of the copolymer were performed on a Mettler TGA/SDTA851 thermogravimetric analysis instrument in a nitrogen atmosphere at a heating rate of $20^{\circ} \mathrm{C} \mathrm{min}^{-1}$ from 200 to $800^{\circ} \mathrm{C}$. Decomposition temperature $\left(T_{\mathrm{d}}\right)$ was taken as the temperature of $5 \%$ weight loss. Temperature for the maximum weight loss rate $\left(T_{\max }\right)$ in nitrogen was also measured at a heating rate of $20{ }^{\circ} \mathrm{C} \mathrm{min}^{-1}$. Char yield $\left(C_{\mathrm{y}}\right)$ was calculated as the percentage of solid residue after heating from 200 to $800{ }^{\circ} \mathrm{C}$ in flowing nitrogen. The glass transition temperature $\left(T_{\mathrm{g}}\right)$ was determined with a Mettler DSC822 differential scanning calorimetry (DSC) in flowing nitrogen at a heating rate of $10^{\circ} \mathrm{C} \mathrm{min}-1$ from 50 to $400^{\circ} \mathrm{C}$. Wide-angle X-ray diffraction (WAXD) and small-angel $\mathrm{X}$-ray diffraction (SAXD) were performed at room temperature on a Rigaku D/max 2400 automatic X-ray diffractometer with Ni-filtered $\mathrm{Cu} \mathrm{K} \alpha$ radiation $(40 \mathrm{~V}, 100$ $\mathrm{mA})$. The texture of the polymer was identified with a Leitz
LABORLUX 12 POLS polarizing light microscopy (PLM) with a TP91 hot-stage.

\section{Polymer Synthesis}

P-5050 was synthesized by the route shown in Scheme 1 . The numbers designating the sample indicated the molar ratios of the comonomers in the reactants. The polymer containing $50 \mathrm{~mol} \%$ (molar percent) DHPZ and $50 \mathrm{~mol} \% \mathrm{BP}$ was depicted as P-5050. A detail procedure for the synthesis of P-5050 was shown as follows:

The polycondensation reaction was carried out in a $100 \mathrm{~mL}$ three-necked round bottom flask outfitted with a mechanical stirrer, a nitrogen inlet, a Dean-Stark trap outfitted with a condenser and a nitrogen outlet. The flask was charged with a mixture of DHPZ (5.0 mmol), BFBB (10.1 mmol), BP (5.0 $\mathrm{mmol})$, potassium carbonate $(14.0 \mathrm{mmol}), 25 \mathrm{~mL}$ sulfolane and $15 \mathrm{~mL}$ toluene. The reaction system was heated to a reflux temperature to promote phenolate formation. Subsequently the polymerization was conducted for $3-5 \mathrm{~h}$ at $200^{\circ} \mathrm{C}$ after completely removing toluene. The resultant reaction mixture was slowly poured into hot water with vigorous stirring in the presence of a little hydrochloric acid, and the resulting polymer precipitated out as fine powders. The dried polymer was subjected to Soxhlet extraction with acetone overnight to produce white powders, and then the powders were dried under vacuum at $120^{\circ} \mathrm{C}$ for $24 \mathrm{~h}$. The yield was $90 \mathrm{wt}$. \%. Elem. Anal. for $\left(\mathrm{C}_{33} \mathrm{H}_{20} \mathrm{O}_{4} \mathrm{~N}\right)_{\mathrm{n}}(494.5)_{\mathrm{n}}$ : Calcd. C 80.15, H 4.08, N 2.83; Found C 80.08, H 4.07, N 2.84.

\section{RESULTS AND DISCUSSION}

\section{Synthesis and Characterization of P-5050}

A one-step aromatic nucleophilic substitution reaction with BFBB, BP and DHPZ was introduced in the synthsis of P-5050 
(Scheme 1). In this reaction system, the two diols BP and DHPZ were used as mesogenic and crystal-disrupting units, respectively. The reaction was accomplished with sulfolane as the reaction medium, toluene as the azeotroping agent in the presence of pottasium carbonate. The premature crystallization phenomenone which led to the precipitating of the copolymer from sulfolane solution prior to the formation of high molecular weight products was observed during the reaction. The molecular weight $\left(M_{\mathrm{n}}\right)$ which was detected by ${ }^{19} \mathrm{~F}$ NMR in concentrated sulfric acid was $4000 \mathrm{~g} \mathrm{~mol}^{-1}$. ${ }^{28}$ And the copolymer was slightly soluble in a mixed solvent of $p$-chlorophenol/ 1, 1, 2, 2-tetracholoroethane. The IR spectrum of P-5050 showed characteristic absorptions at $1650 \mathrm{~cm}^{-1}(v s ., v \mathrm{C}=\mathrm{O})$, $1600 \mathrm{~cm}^{-1}, 1495 \mathrm{~cm}^{-1}$ (s, Ar stretching), $1240 \mathrm{~cm}^{-1}$ (vs., vC-OC) and $1112 \mathrm{~cm}^{-1}(\mathrm{~s}, v \mathrm{~N}-\mathrm{N})$. The Elemental Analysis and IR results suggested that P-5050 was in good agreement with the supposed compositions.

\section{DSC Analysis}

The thermal prperties of P-5050 were evaluated by DSC, and the first cooling and second heating thermograms were depicted in Figure 1. There was only one glass transition temperature at $160^{\circ} \mathrm{C}$ (the second heating curve) and $153{ }^{\circ} \mathrm{C}$ (the first cooling curve). The two main first-order transitions on the second heating process were attributated to a crystalline-toliquid crystalline transition $\left(T_{\mathrm{m}}=333^{\circ} \mathrm{C}\right)$ and a liquid crystalline-to isotropic phase transition $\left(T_{\mathrm{i}}=373^{\circ} \mathrm{C}\right)$, respectively. The reversibility of the phase transitions was evidenced by the presence of two corresponding peaks $\left(T^{\prime}{ }_{i}=345^{\circ} \mathrm{C}\right.$ and $T^{\prime}{ }_{\mathrm{m}}=305^{\circ} \mathrm{C}$ ) in the first cooling process.

In general, the mesophase stability could be expressed by the temperature range $\left(\Delta T=T_{\mathrm{i}}-T_{\mathrm{m}}\right)$ of the thermotropic liquid crystalline material. ${ }^{24}$ According to Wang's results, the effect of geometric repulsive factors on the thermodynamic stability of the mesophase was much larger than that of polarizability attractive factors. ${ }^{22,25-27}$ This indicated that the introduction of bulky, twisted and non-coplanar phthalazinone structure into the mainchain would destabilize the liquid crystalline phase. Consequently, the value of $\Delta T\left(40^{\circ} \mathrm{C}\right)$ was lower than that of other thermotropic liquid crystalline PAEK

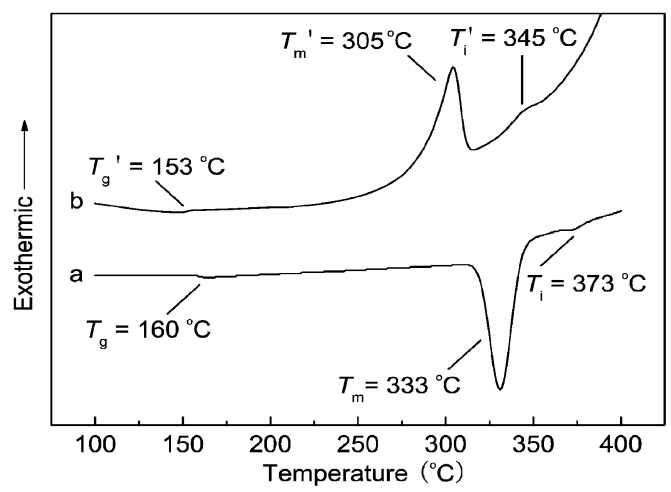

Figure 1. The DSC thermograms of P-5050: (a) the second heating curve. (b) the first cooling curve.

copolymers $\left(>50{ }^{\circ} \mathrm{C}\right) .{ }^{24}$ Moreover, the fact that the heat fusion of melting $\left(\Delta H_{\mathrm{m}}=35.5 \mathrm{~J} \mathrm{~g}^{-1}\right)$ was higher than that of isotropization $\left(\Delta H_{\mathrm{i}}=1.5 \mathrm{~J} \mathrm{~g}^{-1}\right)$ also indicated that no highly ordered mesophase was shaped for P-5050. ${ }^{20}$

The weight loss temperatures $\left(T_{\mathrm{d}}\right)$ of $\mathrm{P}-5050$ was $510^{\circ} \mathrm{C}$ ( $T_{\mathrm{d} 5 \%}$ weight loss percent) (from TGA curve), and the char yield $\left(C_{\mathrm{y}}\right)$ of P-5050 at $800{ }^{\circ} \mathrm{C}$ in nitrogen was $63 \mathrm{wt} . \%$. The temperatures for the maximum of a two steps of weight loss rate $\left(T_{\max }\right)$ in nitrogen were $515^{\circ} \mathrm{C}$ and $575^{\circ} \mathrm{C}$ (from DTG curve), respectively. These resultant data suggested that P-5050 in this study possessed excellent thermal stability.

\section{Thermotropic Behavior}

The liquid crystalline morphology of P-5050 was examined on a PLM under crossed polarizers with a hot stage. P-5050 showed a thread-like texture, when the sample was melted at $410^{\circ} \mathrm{C}$ for $10 \mathrm{~min}$, cooled to the liquid crystalline temperature $\left(320^{\circ} \mathrm{C}\right)$, and annealed at that temperature for $1 \mathrm{~h}$ [Figure 2(A)]. Morever, a typical schlieren texture which related to nematic liquid crystalline phase was formed when shear forces were induced at that temperature [Figure 2(B)]. It should be noted that compared with other poly(aryl ether ketones) copolymers, ${ }^{12}$ the existence of biphenyl mesogen (the axial ratio was larger than $6.42^{29}$ ) and crystal-disrupting phthalazinone moiety in structure together would lead to the
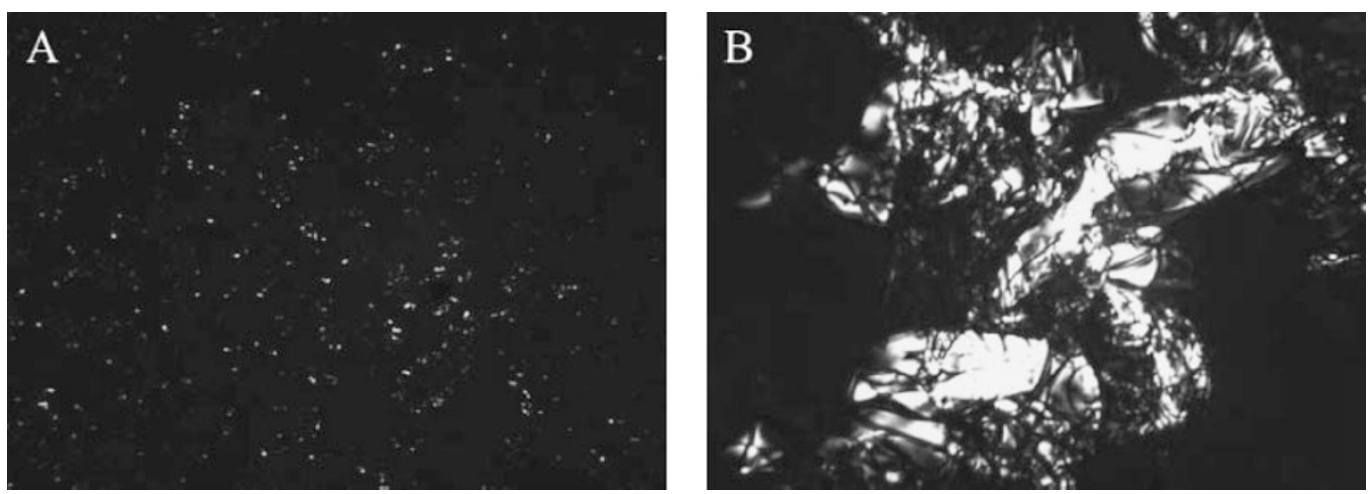

Figure 2. Optical micrographs of $\mathrm{P}-5050$ sample (mag. 20): (A) melted at $410^{\circ} \mathrm{C}$ for 10 min, then cooled to $320^{\circ} \mathrm{C}$ at $10^{\circ} \mathrm{C}$ min ${ }^{-1}$, and maintained at $320^{\circ} \mathrm{C}$ for $1 \mathrm{~h}$ (thread-like texture). (B) melted at $410^{\circ} \mathrm{C}$ for $10 \mathrm{~min}$, then cooled to $320^{\circ} \mathrm{C}$ at $10^{\circ} \mathrm{C} \mathrm{min}-1$, and maintained at $320^{\circ} \mathrm{C}$ for $1 \mathrm{~h}$ with shear forces induced (schlieren texture). 
formation of a liquid crystalline phase for P-5050. ${ }^{26}$ And it was also noteworthy that the formation conditions of thermotropic liquid crystalline texture for P-5050 was a little different from other thermotropic liquid crystalline poly(aryl ehter ketones) copolymers was due to the fact that a phthalazinone structure (bulky, twisted and non-coplanar configureation in steric) in the mainchains would hinder the movement and cubmer the regular packing of the mainchanis significantly. ${ }^{9,12,22}$

\section{SAXD and WAXD Analysis}

The crystallinity of P-5050 which was treated with different methods was characterized by the means of wide-angle Xray diffraction (WAXD) and small-angle X-ray diffraction (SAXD). The fact that no diffraction peak in the SAXD patterns at $2 \theta=0.5$ to $5^{\circ}$ indicated that there was no longdistance order structure between 2 and $3 \mathrm{~nm}$ in the main chain. ${ }^{11}$ As shown in Figure 3(a), the crystalline sample of P5050 showed four strong reflection peaks at $2 \theta=18.7^{\circ}, 19.9^{\circ}$, $23.4^{\circ}$ and $28.9^{\circ}$, which could be assinged as (110), (111), (200) and (211) reflections, respectively, based on orthorhombic packing. ${ }^{12}$ This indicated that $\mathrm{P}-5050$ have a typical structure, which is similar to other regular members of poly(aryl ehter ketones) family. In Figure 3(b), the liquid crystalline sample exhibited only one small diffraction halo at $2 \theta=22^{\circ}$ which suggested the crystal structure was destroyed and shortdistance order $(<2 \mathrm{~nm})$ in the main chain was formed. ${ }^{22}$ Compared with $\mathrm{a}$ and $\mathrm{b}$, no evident diffraction peak could be detected in Figure 3(c) indicated that the crystal structure was completely destroyed and an amorphous pattern was shaped.

\section{CONCLUSIONS}

Synthesis of a novel PAEK copolymer containing DHPZ and BP was achieved through a nucleophilic aromatic substitution in sulfolane solvent in the presence of anhydrous potassium carbonate. The formation of typical nematic liquid crystalline behaviors for P-5050 were verified by the examinations of PLM and WAXD. And the melting transition $\left(T_{\mathrm{m}}\right)$ and isotropization $\left(T_{\mathrm{i}}\right)$ were both observed in the DSC curves. Meanwhile, the novel P-5050 exhibited a wide liquid crystalline temperature range and excellent thermal stability.

Acknowledgment. This work was supported by the National High Technology Research and Development Program of China (863 Program) (No. 2003 AA33G030).

Received: July 30, 2007

Accepted: October 9, 2007 Published: November 20, 2007

\section{REFERENCES}

1. N. Berard and A. S. Hay, Polym. Prepr., (Am. Chem. Soc. Div. Polym. Chem.), 34, 148 (1993).

2. Y. Z. Meng, A. S. Hay, X. G. Jian, and S. C. Tjong, J. Appl. Polym. Sci., 66, 1425 (1997).

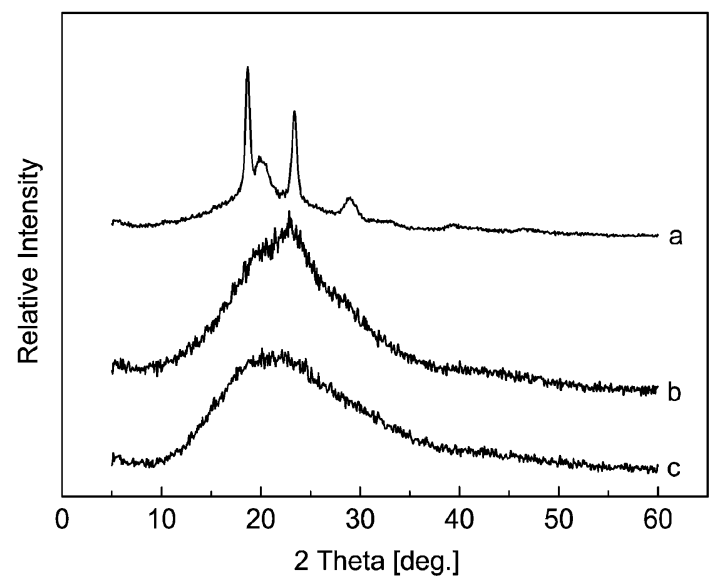

Figure 3. WAXD patterns of P-5050: (a) crystalline sample. (b) liquid crystalline sample. (c) amorphous sample.

3. Y. Z. Meng, A. S. Hay, X. G. Jian, and S. C. Tjong, J. Appl. Polym. Sci., 68, 137 (1998).

4. Y. Z. Meng, A. R. Hill, and A. S. Hay, J. Polym. Sci., Part A: Polym. Chem., 37, 1781 (1999).

5. L. Z. Chen, X. G. Jian, and X. L. Zhu, Polym. J., 31, 393 (1999).

6. L. Z. Chen and X. G. Jian, Polym. J., 31, 560 (1999).

7. Y. J. Liu, X. G. Jian, and S. J. Liu, J. Appl. Polym. Sci., 82, 823 (2001).

8. X. L. Zhu and X. G. Jian, J. Polym. Sci., Part A: Polym. Chem., 42, 2026 (2004).

9. Q. Z. Liang, P. T. Liu, C. Liu, X. G. Jian, D. Y. Hong, and Y. Li, Polymer, 46, 6258 (2005).

10. P. T. Liu, Q. Z. Liang, C. Liu, X. G. Jian, D. Y. Hong, and Y. Li, Polym. J., 38, 477 (2006).

11. P. T. Liu, J. Y. Wang, C. Liu, and X. G. Jian, Macromol. Chem. Phys., 207, 1610 (2006).

12. Q. M. Sun, J. Y. Wang, L. S. He, Y. Song, and X. G. Jian, J. Appl. Polym. Sci., 104, 1744 (2007).

13. Q. M. Sun, J. Y. Wang, C. Liu, Y. Song, and X. G. Jian, Eur. Polym. J., 43, 3683 (2007).

14. W. J. Jackson and H. F. Kuhfuss, J. Polym. Sci., Part A: Polym. Chem., 14, 2043 (1976).

15. R. E. Jerman and D. G. Baird, J. Rheol., 25, 275 (1981).

16. A. Mehta and A. I. Isayev, Polym. Eng. Sci., 31, 971 (1991).

17. G. S. Bennett and R. J Farris, Polym. Eng. Sci., 34, 781 (1994).

18. S. J. Zhang, L. X. Fu, J. J. Liu, D. C. Yang, Z. H. Gao, M. J. Jia, Y. B. Zheng, and Z. W. Wu, Macromol. Chem. Phys., 201, 649 (2000).

19. H. Sun, H. Na, H. F. Wang, W. J. Zhang, Z. W. Wu, and R. Yosomiya, Polym. Int., 49, 1539 (2000).

20. L. X. Fu, S. J. Zhang, J. J. Liu, Z. W. Wu, and D. C. Yang, Macromol. Chem. Phys., 202, 2853 (2001).

21. L. X. Fu, S. J. Zhang, J. Zhang, J. J. Liu, and D. C. Yang, Macromol. Rapid. Commun., 22, 1168 (2001).

22. G. B. Wang, Z. H. Jiang, S. L. Zhang, C. H. Chen, and Z. W. Wu, Polym. Int., 55, 657 (2006).

23. P. M. Hergenrother, B. J. Jensen, and S. J. Havens, Polymer, 29, 358 (1988).

24. A. Coassolo, M. Foa, and D. Dainelli, Macromolecules, 24, 1701 (1991).

25. L. Onsager, Ann. N. Y. Acad. Sci., 51, 627 (1949).

26. P. J. Flory, Proc. R. Soc. London, Ser. A., 234, 60, (1956).

27. W. Maier and A. Saupe, Zaturforsch., A, 13, 564 (1958).

28. J. Devaux, D. Daoust, R. Legras, J. M. Dereppe, and E. Nield, Polymer, 30, 161 (1989).

29. P. J. Flory and G. Ronca, Mol. Crystal. Liq. Cryst., 54, 311 (1979). 